\title{
Reflexões sobre o Lugar do Esporte nas Relações Internacionais*
}

Hugo Suppo**

O esporte é atualmente o espelho através do qual as nações, os homens, as mulheres e as classes sociais se veem. A imagem é, de certa forma, brilhante, às vezes escura, às vezes distorcida e às vezes ampliada. Este espelho metafórico é uma fonte de regozijo e de depressão, de segurança e de insegurança, de orgulho e de humilhação, de união e de desunião. [...] Como o esporte tem atingido uma dimensão colossal, vem progressivamente substituindo a religião no seu poder de excitar a paixão, de proporcionar uma válvula de escape emocional, de oferecer um sentimento de fraternidade (e, cada vez mais, de participação feminina), e tem feito parte, mais e mais, da vida dos europeus e de outros povos.

(J. A. Mangan apud LEVERMORE; BUDD, 2004, p. xi) ${ }^{1}$

\footnotetext{
* Artigo recebido em 27 de agosto de 2012 e aprovado para publicação em 21 de dezembro de 2012. *** Doutor em História das Relações Internacionais pela Universidade de Paris III e professor do Programa de Pós-Graduação em Relações Internacionais (PPGRI) da Universidade Estadual do Rio de Janeiro (UERJ). E-mail: hugorogeliosuppo@mac.com.
}

CONTEXTO INTERNACIONAL Rio de Janeiro, vol. 34, nํㅡ 2, julho/dezembro 2012, p. 397-433. 


\section{Hugo Suppo}

Ele [o esporte] é sempre sério. É organizado: é uma indústria, é um negócio, dinheiro, interesse velado: é resultado e transmissor de ideologia, de prestígio, de status, de nacionalismo, de internacionalismo, de diplomacia e de guerra.

(Colin Tatz apud HOULIHAN, 1994, p. 1)

\section{Introdução}

Nos próximos anos o Brasil será sede dos dois megaeventos esportivos mais importantes do planeta: a Copa Mundial de Futebol e as Olimpíadas. Em meio à intensa mobilização do país na preparação desses eventos, muito se discute na mídia e nas redes sociais sobre as consequências econômicas, sociais e políticas geradas por essa incorporação plena do Brasil na chamada economia internacional do entretenimento.

Essa movimentação que o país vive em torno ao esporte contrasta vivamente com a ausência praticamente total do tema na produção acadêmica brasileira na área das Relações Internacionais, mesmo entre os autores que privilegiam abordagens menos tradicionalistas. $\mathrm{O}$ objetivo deste trabalho é chamar a atenção para essa situação e apresentar uma introdução ao estudo do esporte nas Relações Internacionais. Em primeiro lugar, será apresentado um balanço bibliográfico da questão na área da história das Relações Internacionais e, mais especificamente, na área das Relações Internacionais. Em segundo lugar, serão analisadas algumas obras recentes que colocam um fim relativo ao que foi considerado pelos especialistas como uma "negligência" pelo esporte no mainstream da disciplina. A apresentação dessas sugestões de pesquisas e de debates acerca de qual seria o paradigma mais adequado para tratar do tema objetiva suscitar futuras pesquisas sobre o assunto no Brasil, que necessariamente deverão ser pluridisciplinares, dada a complexidade do fenômeno.

O esporte foi intensamente politizado no interior dos Estados-nações europeus durante o século XIX, quando é usado como vetor da iden- 
tidade nacional em Estados multinacionais e revelador do prestígio nacional. Entretanto, naquela época, o esporte era ainda relativamente marginal e elitista, exceto no caso do futebol e do ciclismo ${ }^{2}$ (HOBSBAWM, 1997, p. 298-299).

A maioria dos esportes modernos (corridas de cavalos, futebol, luta, boxe, tênis, caça à raposa, remo, críquete e atletismo) teve origem na Inglaterra, mas, no final do século XIX, eles já apresentavam uma tendência a se internacionalizar com a organização dos Jogos Olímpicos e a criação das federações internacionais. O olimpismo, nascido na virada do século XIX para o XX, no contexto de proliferação de nacionalismos imperialistas fundamentados no darwinismo social e racial, carrega desde sua origem um paradoxo: os ideais cosmopolita, fraternal, elitista, apolítico, paternalista, pedagógico e antimercantil coexistem com a força das ideologias, da política, dos interesses e as exclusões.

Segundo Norbert Elias, essa propagação dos esportes modernos no resto do mundo, em primeiro lugar as corridas de cavalos, o pugilismo, a caça à raposa e, depois, na segunda metade do século XIX, os jogos de bola, como o futebol e o tênis, não foi resultado do imperialismo cultural inglês. Tratar-se-ia de uma atividade com certa autonomia individual e social:

Por que é que, por exemplo, algumas das variedades iniciais de desportos ingleses, tais como o futebol e o tênis, foram adotadas por muitas sociedades diferentes, em todo o mundo, enquanto a expansão do críquete se confinou principalmente a um círculo exclusivo dos países da Commonwealth? Por que é que uma variedade do futebol, o rúgbi, não se expandiu tão largamente como o futebol? Por que é que os Estados Unidos, sem abandonarem por completo as variantes do desporto inglês, desenvol- 


\section{Hugo Suppo}

veram a sua própria variedade de futebol? (ELIAS; DUNNING, 1992, p. 67).

Independentemente das razões (imposição ou aceitação), o fato é que a internacionalização do esporte realmente só se acentua após a Primeira Guerra Mundial no contexto do surgimento da comunicação de massa, que transforma o esporte em espetáculo. Isso suscita o interesse dos homens de Estado, que começam a considerá-lo um instrumento de política externa não desprezível.

Nesse sentido, o primeiro país a adotar uma política esportiva para o exterior foi a França, quando criou, em 1920, no interior do Service des Euvres Françaises à l'Étranger (Serviço das Obras Francesas no Exterior), dependente do Ministère des Affaires étrangères (Ministério das Relações Exteriores), uma "Section du tourisme et de esport" (Seção turismo e esporte).

Para alguns países, o esporte constitui atualmente um elemento do chamado soft power. O Brasil, por exemplo, segundo Nye possui dois elementos essenciais de soft power no plano internacional - "a cultura popular do carnaval e do futebol"3 (NYE, 2012, p. 224) -, e a China teria aumentado o seu com a organização das Olimpíadas de 2008 (NYE, 2012, p. 11).

A não participação nos megaeventos esportivos é, para qualquer Estado, um considerável prejuízo, e isso denota, em grande medida, o enorme poder que concentram as organizações não governamentais que gerenciam o esporte. O Comitê Olímpico Internacional (COI), ${ }^{4}$ por exemplo, é integrado por 115 membros; uma parte deles são representantes das federações internacionais do esporte e representantes dos comitês nacionais olímpicos, e outra parte, setenta deles, são personalidades muitas vezes mais ligadas ao jet set do que ao movimento esportivo propriamente dito. 


\section{Reflexões sobre o Lugar do Esporte nas Relações Internacionais}

A FIFA é a outra ONG do esporte importante. Ela conta hoje com 209 associações membros (nacionais ou não, já que, por exemplo, a Grã-Bretanha é representada por Inglaterra, Escócia, Irlanda do Norte e País de Gales). Atualmente, só são aceitos como novos membros países que tenham de fato obtido sua independência; dessa maneira, o último membro integrado foi o Sudão do Sul, em maio de 2012.

\begin{tabular}{lcc} 
Quadro 1 & $\begin{array}{c}\text { Número de federações } \\
\text { afiliadas à FIFA }\end{array}$ & $\begin{array}{c}\text { Número de países membros da } \\
\text { Liga das Nações ou da ONU }\end{array}$ \\
\hline 1904 & 7 & 0 \\
1914 & 24 & 0 \\
1920 & 20 & 42 \\
1923 & 31 & 43 \\
1930 & 41 & 41 \\
1938 & 51 & 38 \\
1950 & 73 & 60 \\
1954 & 85 & 76 \\
1959 & 95 & 99 \\
1984 & 150 & 159 \\
1991 & 165 & 166 \\
1994 & 190 & 185 \\
2010 & 208 & 192 \\
\hline
\end{tabular}

Fonte: Boniface (2010, p. 45)

Os dirigentes da maioria das ONGs do esporte permanecem nos cargos durante muito tempo. Por exemplo, Julio Grondona ocupa a presidência da Associação do Futebol Argentino (AFA) desde 1979. Não devemos esquecer que, desde então, nessas cinco décadas, quinze chefes de Estado passaram pela Casa Rosada (incluindo os presidentes militares da última ditadura de 1976 a 1983), e o país viveu terríveis crises econômicas, políticas e sociais. Nem mesmo as dezenas de denúncias nos tribunais argentinos conseguiram abalar seu domínio.

As ONGs do esporte conseguem impor suas vontades aos governos. Segundo Rick Mkhondo, diretor de Comunicações do Comitê Orga- 


\section{Hugo Suppo}

nizador da África do Sul durante a Copa do Mundo de 2010, a FIFA obrigou o governo sul-africano a assinar dezessete acordos, posteriormente consolidados na chamada "Lei de Medidas Especiais de 2006 para a Copa do Mundo FIFA de 2010". A FIFA, ademais de se reservar todos os direitos de mídia e marketing, teria mesmo chegado a proibir o uso do termo "República da África do Sul (RSA) 2010” e “África do Sul 2010”. Mkhondo (2012, p. 7) denuncia:

Afinal de contas, eles não pagam nenhum tipo de imposto, ignoram o controle cambial, comercializam todos os aspectos do evento, reservam os direitos autorais de palavras como "World Cup", aparentemente cobram preços exorbitantes, declaram "zonas de exclusão", silenciam jornalistas com exigências para acreditação que incluem não expressar críticas, e são muitas vezes vistos como um atentado à liberdade de expressão. [...] O órgão baseado em Zurique é muitas vezes comparado a um governo soberano, e tem um poder que faz com que os governos se dobrem às suas exigências, $o$ que lhes permite ditar as regras do jogo com impunidade.

Alguns podem dizer que isso é o que permite que o futebol funcione e prospere em nível global. Outros podem dizer que é a arrogância da Fifa que ajuda a engordar os seus cofres, com reservas financeiras de quase US $\$ 1,3$ bilhão, um montante maior do que a produção econômica anual de alguns países.

De fato, as ONGs do esporte têm uma autonomia enorme. Por exemplo, a Carta Olímpica, em vigor desde 1894, instaurou um autêntico sistema de direito internacional paralelo ao direito internacional público. Durante o entreguerras, conscientes da importância do esporte nas questões sanitárias, educativas e geopolíticas, alguns Estados tentaram, sem sucesso, colocar o COI sob jurisdição da Liga das Na- 
ções. Entretanto, a lex olimpica estabelece, após a revisão de 1990, que as relações entre o COI (associação de direito internacional com personalidade jurídica) e o Estado ou a cidade organizadora dos jogos não são regidas pelo "direito internacional dos contratos", mas sim pelo direito privado suíço (LATTY, 2009, p. 4-5).

Dessa forma, os atores decisivos dessa internacionalização do esporte não são apenas os responsáveis políticos dos governos e partidos, mas também os dirigentes esportivos das federações nacionais, internacionais ${ }^{5}$ e do movimento olímpico. Outros atores também são importantes: os jornalistas, os próprios esportistas, os espectadores e a opinião pública.

Na chamada cultura da mídia (KELLNER, 2006), que se torna hegemônica a partir dos anos 1970, o espetáculo tornou-se um dos princípios organizacionais da sociedade, da economia, da política, da cultura e da vida cotidiana. Ele não só fornece o material para os sonhos e as fantasias como constrói as identidades. Nesse sentido, os esportes ocupam um lugar privilegiado, junto com o cinema, a televisão, o teatro, a moda, a arquitetura contemporânea, a música popular, o erotismo e os videogames e jogos de computador. As celebridades do esporte são "divindades" que foram fabricadas e permanentemente valorizadas positivamente ante o público pelos assessores e agentes de imagem. ${ }^{6}$ São verdadeiros produtos que vendem outros produtos e imagens, não necessariamente ligados ao mundo do esporte. ${ }^{7}$

Entretanto, o espetáculo, por ser "sempre contraditório, ambíguo e sujeito a inversões e reviravoltas" (KELLNER, 2006, p. 143), pode servir não só para novas formas de dominação e opressão, como também para a justiça social e a democratização das sociedades.

Os esportes há muito têm sido propícios ao espetáculo, com eventos como as Olimpíadas, World Series, Super Bowl, a Copa do Mundo e os campeonatos de basquete da NBA atraindo audiências maciças e gerando anúncios a pre- 


\section{Hugo Suppo}

ços astronômicos. Esses rituais culturais celebram os valores mais profundos da sociedade (por exemplo, a competição, o sucesso e o dinheiro), e as empresas estão dispostas a investir vultosas verbas para que seus produtos se associem a tais eventos. Realmente, parece que a lógica da mercadoria do espetáculo está tão inexoravelmente entranhada nos esportes profissionais que estes não podem mais existir sem o acompanhamento de torcidas animadas, mascotes gigantes que brincam com os jogadores e espectadores, sorteios, promoções e competições envolvendo os produtos de diversos patrocinadores (KELLNER, 2006, p. 128).

Partindo da constatação de que o esporte é um fenômeno multifacetado extremamente importante e que não é apolítico, o objetivo deste ensaio é fazer uma análise da forma como ele foi abordado pelos historiadores e pelos especialistas da área de Relações Internacionais e fornecer subsídios para futuras pesquisas sobre o assunto no Brasil.

\section{O Esporte na História das Relações Internacionais}

Nos últimos anos, a pesquisa histórica sobre o esporte fez grandes progressos, e velhos mitos foram destruídos. Por exemplo, o de que foram os Estados autoritários e totalitários os primeiros a utilizar o esporte na propaganda externa (ARNAUD, 1998, p. 278-280; 2002, p. 353-356). No Tratado de Versalhes (1919), inúmeras são as imposições contra os países vencidos e considerados culpados da guerra, mas nenhuma é referente ao esporte. Entretanto, é nessa área que as sanções serão particularmente duras, iniciando-se assim a difundida prática de utilização do esporte como meio de propaganda e de pressão diplomática no âmbito das relações internacionais. O mais surpreendente nesses acontecimentos é que foram os países democráticos os primeiros a usar esse recurso e não, como seria de esperar, os 
regimes totalitários. Tampouco foi um recurso utilizado contra Estados autoritários, já que nessa época a Alemanha vivia a experiência da República de Weimar. Na realidade, o primeiro boicote foi feito pelo novo Estado soviético, ao se recusar a participar de competições internacionais que considerava burguesas (RIORDAN, 1991, p. 127).

Não obstante, em 1984, Pierre Milza constata que, apesar desses progressos pontuais nos estudos históricos, eram raros os trabalhos sobre o esporte no âmbito da história, da ciência política e da sociologia. Pouco útil tinha sido o dinamismo da International Association for Sports Information (IASI), que tinha sido fundada em 1960, e a posterior criação de inúmeros centros de estudos nas universidades europeias e nos Estados Unidos, Canadá e Austrália: ainda dominavam, na época, as obras que ele denomina de "jornalísticas-hagiográficas", de péssima qualidade, com ausência de sínteses. Isso lhe parecia surpreendente, pois se tratava de um fenômeno de massa e universal, ${ }^{8}$ compatível com todas as ideologias, indicador do grau de potência (ou de declínio) de um Estado, revelador e manipulador do sentimento popular (seja como "fábrica de consenso" ou como instrumento de estratégias defensivas ou ofensivas), substituto da guerra e instrumento da diplomacia. O esporte tinha se transformado em espetáculo e se prestava para a manipulação, não só pelos interesses financeiros, mas também pelos partidos de massa e pelos ditadores de toda espécie (MILZA, 1984, p. 156-157).

Esse balanço pessimista de Milza deve ser matizado, já que nas suas reflexões, por razões que não cabe discutir aqui, ele praticamente ignora a produção acadêmica do mundo anglo-saxão, como veremos mais adiante.

De todas maneiras, a contribuição dos historiadores francófonos será muito importante. ${ }^{9}$ A revista Relations Internationales dedica, em 1984, um número especial ao tema "Sport et relations internationa- 
les" (nํㅜㄹ). O objetivo desse número não é fazer um balanço historiográfico, tampouco apresentar ensaios de teorização sobre o tema, mas apenas suscitar debates. Dessa forma, os temas tratados são: a gênese do chamado "prestígio nacional" associado ao esporte, como forma particular de nacionalismo; a "diplomacia esportiva internacional" francesa durante o entreguerras e na Guerra Fria; os Jogos Olímpicos (compreensão internacional ou terreno de enfrentamento?); o futebol internacional e seus símbolos e realidades.

Pierre Milza (1984, p. 163-171), no artigo que serve de apresentação da revista, afirma que o esporte possui três dimensões essenciais na política internacional:

1. é componente e reflexo da vida internacional;

2. é revelador do sentimento público; e

3. tem papel relevante em três aspectos precípuos da política estrangeira:

- como instrumento de preparação para a guerra, através dos fins guerreiros da educação física e das atividades esportivas (o cidadão soldado);

- engendrando imagens de prestígio que podem ser instrumentalizadas pela propaganda nacionalista; e

- como meio de aproximação entre os países (o mesmo papel que tinham as visitas das esquadras navais no século XIX).

As observações de Milza são extremamente relevantes, pois de fato o esporte é competitivo por natureza e seus resultados são intangíveis (prestígio) e, ao mesmo tempo, tangíveis, já que podem ser facilmente medidos por meio dos resultados dos diferentes jogos e campeonatos. ${ }^{10}$ Nesse sentido, o quadro de medalhas ${ }^{11}$ é o melhor termômetro comparativo do sucesso. Por outro lado, todos os atletas têm, em princípio, as mesmas chances de sucesso, independentemente do poder do Estado que representam. Por exemplo, em 2003, Kim Collins, 
da minúscula ilha-Estado de São Cristóvão e Neves, ganhou a medalha de ouro de atletismo.

Em 2002, é realizado, em Lausanne, na sede do Museu Olímpico do COI o colóquio “Olimpismo e Relações Internacionais”, por iniciativa do Centro de Estudos Olímpicos, da revista Relations Internationales, do Institut Universitaire des Hautes Études Internationales de Genebra e do departamento de história da Faculdade de Letras da Universidade de Lausanne. Os trabalhos apresentados nesse colóquio foram publicados na revista Relations Internationales, em dois números dedicados ao "Olympisme et relations internationales" $\left(\mathrm{n}^{\mathrm{os}} 111\right.$ e 112,2002). Os principais temas abordados ${ }^{12}$ são os seguintes:

1. a gênese do olimpismo hodierno, no contexto do enfrentamento entre os nacionalismos europeus e o pacifismo liberal;

2. as consequências do Tratado de Versalhes e da revolução bolchevique no esporte e no olimpismo (boicotes);

3. o COI e as rivalidades franco-alemãs (1918-1928);

4. olimpismo e Guerra Fria: a diplomacia esportiva, instrumento para atenuar o declínio francês (1948-1952); a diplomacia esportiva soviética e os Jogos Olímpicos de Helsinki (1952); o boicote americano aos Jogos Olímpicos de Moscou (1980);

5. o olimpismo como barômetro das relações de potência entre os Estados;

6. o papel da Agência Mundial Antidoping, criada em 1999;

7. Olimpíadas e globalização;

8. movimento olímpico e meio ambiente/ecologia; e

9. a dimensão econômica e mediática da organização dos Jogos Olímpicos.

Esses trabalhos constituem uma contribuição importante no sentido de ressaltar certos temas, fornecer elementos factuais e estimular pesquisas futuras. Passemos agora à análise da produção bibliográfica ligada diretamente à disciplina de Relações Internacionais. 


\section{O Esporte nas Relações Internacionais}

Em 1976, a Unesco organizou a Primeira Conferência Internacional de Ministros e Altos Funcionários Responsáveis por Educação Física e Desporto, da qual participaram delegados de 102 países. O objetivo era fomentar a cooperação internacional através do esporte, considerado por muitas nações como uma força cultural essencial.

Entretanto, o estudo do esporte não consegue penetrar no círculo mainstream das ciências políticas apesar da enorme proliferação de revistas científicas especializadas no estudo sociológico do esporte (Sport in Society, Sociology of Sport Journal, International Journal for the Sociology of Sport, Soccer and Society, International Journal of Sport Policy etc.). As causas de tal "negligência" na área acadêmica de Relações Internacionais se encontram, essencialmente, no domínio da abordagem realista, preocupada apenas em questões ligadas ao poder econômico, militar e político. Pascal Boniface, diretor do Institut de Relations Internationales et Stratégiques (IRIS), lembra a resistência de seus colegas quando ele organizou, em 1998, um colóquio sobre a "Geopolítica do Futebol”. Segundo ele, o tema, que já tinha sido bastante estudado pelos sociólogos, economistas e cientistas políticos, era considerado pouco sério pela academia na área das Relações Internacionais (BONIFACE, 2010, p. 14).

Na realidade, o tema do esporte nas relações internacionais já tinha despertado a curiosidade de alguns estudiosos anglo-saxões, injustamente ignorados por Boniface e também, como já vimos, por Pierre Milza. Por exemplo, em 1978, é publicada uma compilação de artigos, Sport and International Relations (LOWE et al., 1978), que será, segundo Trevor Taylor (1986, p. 47), durante quase uma década o único livro especificamente voltado para os estudantes de Relações Internacionais interessados no esporte. Nessa obra, sete temas são abordados: 
1. esporte e nacionalismo (identidade nacional);

2. as Olimpíadas e os interesses políticos dos Estados e grupos (por exemplo, as Olimpíadas de Berlim, em 1936);

3. propaganda ideológica e esporte;

4. o esporte como instrumento da política externa (prestígio, reconhecimento, cooperação, boicote etc.):

a. o uso do esporte pelas superpotências durante a Guerra Fria e a détente;

b. a instrumentalização do esporte pela diplomacia (estudos de caso): China ("friendship first, competition second" [amizade em primeiro lugar, competição em segundo] e a "Ping-Pong Diplomacy" [diplomacia do pingue-pongue]), República Democrática Alemã (RDA), África do Sul (a questão do apartheid) e Canadá;

c. as interseções entre a política esportiva interna e a política externa;

d. esporte e a public diplomacy (diplomacia pública);

e. o esporte e as novas nações independentes surgidas na descolonização: esporte e nova identidade nacional (nation building); esporte como instrumento para o não alinhamento: Games of the New Emerging Forces (GANEFO);

5. o papel das organizações governamentais e não governamentais do esporte;

6. esporte e integração regional: o papel da European Sport for All Charter, de 1975; e

7. o papel do esporte na atual sociedade de consumo.

Na época da publicação desse livro, do qual é um dos organizadores conjuntamente com B. Lowe e A. Strenk, David B. Kanin era ${ }^{13}$ professor de Política Internacional e Sistemas Políticos Europeus, no Boston College, Massachusetts (atualmente é professor de Relações Internacionais na Johns Hopkins University e professor de Estudos Europeus e analista sênior na Agência Central de Inteligência 


\section{Hugo Suppo}

[CIA] $).{ }^{14}$ Na coletânea, Kanin é o autor dos três artigos mais interessantes do ponto de vista teórico: "Superpower Sport in Cold War and Detente" (p. 249-262), "Ideology and Diplomacy: The International Dimensions of Chinese Political Sport" (p. 263-278) e "The Olympic System: Transnational Sport Organization and the Politics of Cultural Exchange" (p. 515-537).

No último artigo, ele afirma - inspirado na nova abordagem da interdependência complexa (que ele denomina pluralismo), que marcou os debates interparadigmáticos da época, desenvolvida por Keohane e Nye (1972) - que o esporte é uma "forma de atividade cultural" com enorme importância no sistema internacional:

Na era contemporânea, as relações internacionais estão mais do que nunca sob o escrutínio público. As relações interculturais devem ser objeto de um estudo cuidadoso como parte integrante do sistema internacional. Uma análise do processo que faz parte de qualquer intercâmbio é mais importante na determinação do significado político, bem como humanitário ou cultural, de uma transação do que as tradicionais distinções entre as atividades que são consideradas "importantes" e as que não o são (KANIN, 1978, p. 533).

Entretanto, o esporte, adverte Kanin, diferencia-se das outras atividades culturais em três questões fundamentais:

1. a maioria dos envolvidos profundamente nas questões esportivas são participantes indiretos das mesmas (público, jornalistas, políticos etc.);

2. sendo uma atividade competitiva por natureza - a rivalidade faz parte de sua essência-, o esporte simboliza formas alternativas de guerra e conflito aberto;

3. os espectadores são os atores mais importantes, e não os atletas. 
Essa singularidade do esporte faz então com que os Estados estejam particularmente interessados nele:

Atletas e dirigentes esportivos muitas vezes desenvolvem boas amizades com seus colegas provenientes, até mesmo, dos Estados mais hostis. Não é o atleta, no entanto, que é o agente mais importante no processo, e sim o espectador. Ele é o alvo nas comparações nacionais e ideológicas intrínsecas ao processo. É nessa atmosfera que muitos Estados criaram órgãos do governo para coordenar a atividade esportiva.

O uso do esporte para transmitir uma mensagem diplomática ou para promover a identificação entre o cidadão e o Estado é hoje um fenômeno regularizado e sistematizado. Isso é verdade mesmo que os órgãos do esporte internacional permaneçam funcionalmente autônomos. Questões relativas à conduta do esporte são tratadas dentro da organização do esporte. Este último é um mecanismo autossuficiente no que diz respeito às reivindicações rivais feitas pelos participantes diretos da competição esportiva (KANIN, 1978, p. 519).

Como já dissemos, desde a publicação em 1978 da compilação de artigos acima citada, praticamente nada foi publicado sobre o tema no mundo anglo-saxão até a edição de outros três trabalhos essenciais:

1. "Sport and International Relations", de Trevor Taylor, publicado em livro organizado por Lincoln Allison (1986);

2. "Representing World Politics: The Sport/War Intertext", de Michael J. Shapiro, publicado no livro de M. Shapiro e J. Der Derian (1989), International/Intertextual Relations - Posmodern Readings of World Politics; e

3. Sport and International Politics, livro de Barrie Houlihan (1994).

O primeiro livro é a publicação dos trabalhos apresentados na conferência anual da Political Studies Association, em Manchester, em 
1985. Trevor Taylor constata, no referido texto, que os livros de Relações Internacionais praticamente ignoravam até então a questão do esporte, ou apenas destinavam algumas linhas para comentar o tema. Nesse sentido, é muito revelador que a chamada escola inglesa, particularmente interessada nos fatores culturais, tenha ela também praticamente ignorado o tema. Por exemplo, Hedley Bull, em seu livro A sociedade anárquica, publicado em 1977, tem uma única referência ao esporte, quando se refere às organizações desportivas (BULL, 2002, p. 313).

Entre o esporte e as Relações Internacionais, havia o que Taylor (1986) chama de "negligência mútua" (o título do seu texto é muito claro, "Sport and International Relations. A Case of Mutual Neglect"), já que ambos consideravam que operavam em domínios separados. Isso lhe parecia surpreendente dado o papel que o esporte tinha adquirido como elemento significativo nos assuntos internacionais e pelo fato de que os próprios governos consideravam o esporte importante demais para ser ignorado. Apesar do esporte não estar no centro das relações intergovernamentais, nem ter importância essencial nas questões de segurança e econômicas, o mesmo deveria, segundo ele, ter sido mais estudado pelos especialistas nas relações internacionais, por quatro razões:

1. é um fator de enorme importância social e cultural;

2. a crescente internacionalização do esporte o tornou parte do sistema internacional, que, apesar de ser um sistema anárquico, pode ser influenciado pela interdependência que o esporte cria;

3. o esporte é um instrumento formidável para a política governamental;

4. as organizações privadas internacionais que se ocupam do esporte são muito importantes e deveriam ter sido estudadas no quadro da análise global das organizações internacionais e transnacionais (TAYLOR, 1986). 
A partir do início dos anos 1980, com a publicação das primeiras críticas radicais contra o neorrealismo de Kenneth Waltz (1979), inicia-se uma série de manifestações que contestam a supremacia das abordagens teóricas dominantes (neorrealista e liberal) naquele momento nas Relações Internacionais. ${ }^{15} \mathrm{O}$ texto referido de Michael Shapiro, professor de Ciência Política na Universidade do Havaí, "Representing World Politics: The Sport/War Intertext", faz parte de uma obra coletiva (SHAPIRO; DER DERIAN, 1989) que pretende apresentar uma análise das relações internacionais do ponto de vista do pós-modernismo. A influência de Michel Foucault, Jacques Derrida, Roland Barthes e Jacques-François Lyotard é fundamental nessa abordagem e no texto citado: o mundo não é uma realidade objetiva que possa ser estudada, mas uma construção, um texto, ou melhor, um intertexto que apenas é acessível por meio da interpretação ou das reinterpretações que o pesquisador formule. O objetivo é desmistificar os conceitos vigentes (por exemplo, a anarquia do sistema internacional e a soberania dos Estados), problematizar as evidências e convenções, acabar com os fetiches e os "regimes de verdade". Nesse sentido, o texto de Shapiro analisa como os discursos sobre o esporte, cujos significados já foram designados pela cultura e aprendidos na vida cotidiana, servem como "stock of signs" (estoque de sinais) que permitem que a economia, a política e a guerra possam ter seu sentido figurado em termos de esporte. Dessa forma, as metáforas esportivas permitem mobilizar os indivíduos.

O terceiro trabalho citado é de Barrie Houlihan, sociólogo, professor desde 1998 de Sport Policy (Política do Esporte) na Universidade de Loughborough, Reino Unido, membro desde 2011 da Academia de Ciências Sociais da Inglaterra, e também editor da International Journal of Sport Policy. Esta revista, criada em janeiro de 2009, publicou, numa ótica pluridisciplinar e comparativa, importantes contribuições sobre o papel das organizações governamentais transnacionais (União Europeia, Agência Mundial Antidoping, UNESCO, 


\section{Hugo Suppo}

Conselho da Europa) e das ONGs (Comitê Olímpico Internacional, federações internacionais) em relação à regulação e ao desenvolvimento do esporte.

É importante ressaltar aqui que praticamente a totalidade dos trabalhos existentes sobre o tema não foi produzida na área das Relações Internacionais, nem por historiadores ou sociólogos, mas por especialistas nos estudos sobre o esporte. Podemos citar como exemplo o caso de Benjamin Lowe, autor da citada primeira compilação de artigos sobre esporte e relações internacionais, que era formado em filosofia e lecionava na Faculdade de Educação da Governors State University, Illinois. ${ }^{16}$ Podemos dizer a mesma coisa de Lincoln Allison, ${ }^{17}$ de James Riordan, ${ }^{18}$ de Pierre Arnaud ${ }^{19}$ e Barrie Houlihan.

A situação é análoga no Brasil. Os livros publicados sobre o tema (que não serão analisados neste ensaio) são obra, essencialmente, de historiadores, sociólogos, jornalistas e antropólogos (DRUMOND, 2008; MELO; DRUMOND, 2009; MELO et al., 2010; HELAL, 2011, para citar os mais recentes). O texto mais importante sobre o tema escrito por um especialista em Relações Internacionais é uma monografia de fim de curso do Instituto Rio Branco, de Douglas Wanderley de Vasconcellos, publicada em 2011. Infelizmente, o autor está mais interessado em fornecer, como ele mesmo afirma, um "receituário de propostas para uso do esporte na projeção da imagem externa do Brasil" (VASCONCELLOS, 2011, p. 25) do que em efetuar uma análise acadêmica do assunto.

Barrie Houlihan (1994, p. 25) lamenta também que o tema tenha sido pouco abordado na área:

Apesar de muitos dos estudos sobre os Jogos Olímpicos lidarem com uma gama de assuntos relacionados às relações internacionais, existem poucos estudos objetivando ser uma exploração mais abrangente da importância do esporte para a política internacional (Allison, 
1986; Lowe et al 1978 são duas importantes exceções).

Houlihan é o único autor que estabelece, explicitamente, um panorama geral da possível relação entre as três teorias ou paradigmas gerais das Relações Internacionais com o esporte. Sua contribuição é essencial para poder desenvolver futuras análises teóricas. Seu objetivo é apresentar de forma sintética como esses paradigmas (realismo, pluralismo e globalismo) poderiam abordar o papel e o significado do esporte na política internacional. Para tal fim, em primeiro lugar, estabelece uma tipologia, a partir dos três tipos de atores ou agentes nas relações internacionais (Estados e organizações internacionais governamentais; organizações não governamentais internacionais; indivíduos) e do grau de envolvimento e interação dos diferentes recursos (finanças, indivíduos, conhecimento/cultura e território):

Em segundo lugar, o autor conclui que a abordagem teórica mais adequada para tratar do tema do esporte nas relações internacionais é o pluralismo. $\mathrm{O}$ realismo e o globalismo seriam paradigmas menos convenientes por centralizarem as explicações num único fator. $\mathrm{O}$ primeiro, nas questões políticas e tendo seu foco de análise centrado em um único ator, o Estado, e com uma preocupação concentrada na segurança. O segundo, nas relações econômicas de dependência e dominação.

A partir do texto de Houlihan, elaboramos um quadro sintético dos temas que, segundo o autor, fariam parte do interesse específico de cada um dos diferentes paradigmas teóricos, conforme Quadro 3 a seguir.

Entretanto, como já dissemos, apesar de o esporte constituir um tema interessante para todas as teorias, o pluralismo é considerado a abordagem mais adequada, e é adotada pelo autor no resto do $l i v r o^{20}$ pelas seguintes razões: 


\section{Hugo Suppo}

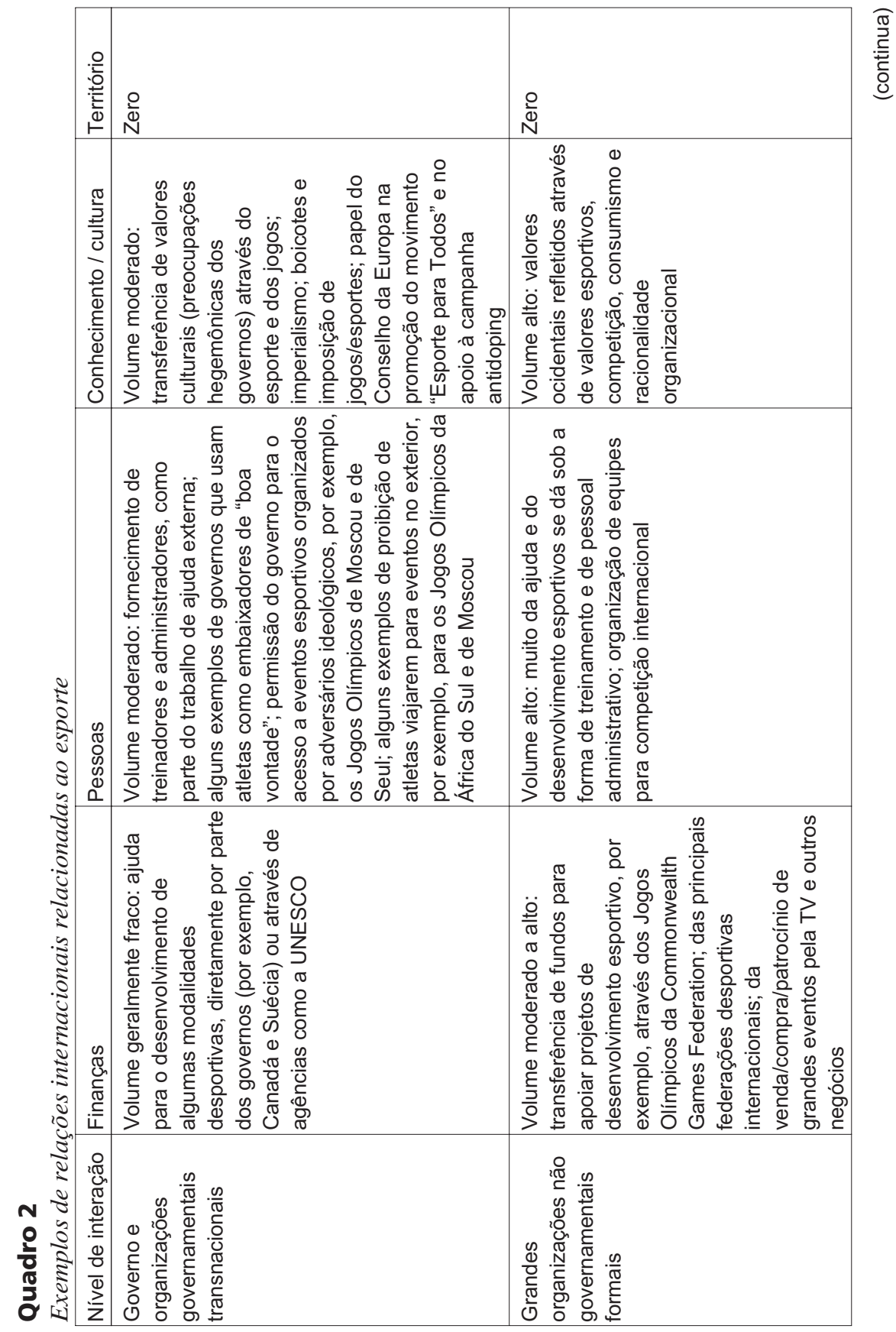


Reflexões sobre o Lugar do Esporte nas Relações Internacionais

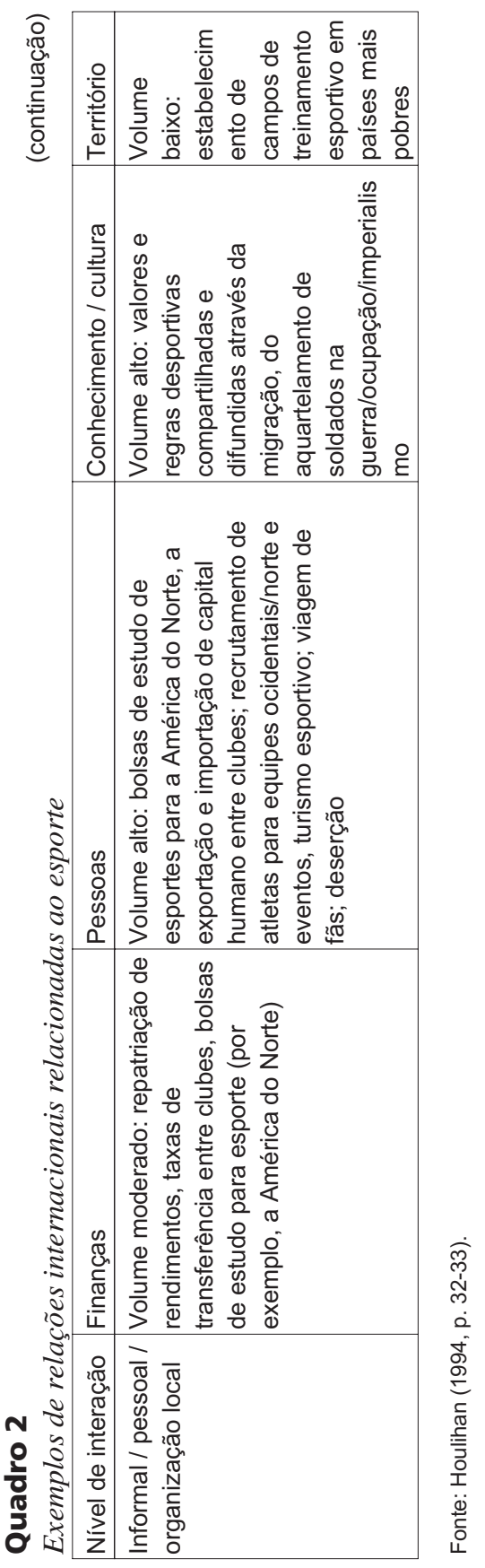




\section{Hugo Suppo}

\section{Quadro 3}

\begin{tabular}{|c|c|}
\hline Realismo & $\begin{array}{l}\text { - uso do esporte como instrumento da política externa: } \\
\text { a. meio para o reconhecimento da soberania nacional (por } \\
\text { exemplo, o caso da República Popular da China e da RDA) } \\
\text { b. válvula de segurança em momentos de tensão internacional } \\
\text { (por exemplo, a "ping-pong diplomacy" entre os Estados } \\
\text { Unidos e a China) } \\
\text { c. meio para melhorar as relações entre os Estados (por } \\
\text { exemplo, a "baseball diplomacy" dos Estados Unidos com o } \\
\text { México e o Panamá) } \\
\text { - esporte e identidade nacional (aumento de poder) } \\
\text { - esporte considerado como uma parte do "cultural package" não } \\
\text { militar, essencial no estabelecimento e manutenção da hegemonia } \\
\text { das grandes potências }\end{array}$ \\
\hline Pluralismo & $\begin{array}{l}\text { - o papel das organizações não governamentais do esporte (por } \\
\text { exemplo, COI e FIFA) como atores independentes na política } \\
\text { internacional e suas interações com os Estados } \\
\text { - o papel da mídia esportiva }\end{array}$ \\
\hline Globalismo & $\begin{array}{l}\text { - o papel das corporações multinacionais ligadas ao esporte } \\
\text { (marketing, mídia, equipamento esportivo etc.) na dominação do } \\
\text { capitalismo global } \\
\text { - exportação de esportistas talentosos dos países pobres para os } \\
\text { países ricos } \\
\text { - esporte como meio de ação do imperialismo cultural }\end{array}$ \\
\hline
\end{tabular}

[...] a perspectiva pluralista oferece uma estrutura muito mais favorável à análise, particularmente no que diz respeito ao reconhecimento explícito da importância das ONGs e a sua preocupação com os processos políticos. Uma perspectiva do sistema internacional que enfatize uma multiplicidade de interesses e de recursos e que reconheça a importância, para os Estados, de questões que ultrapassem o escopo das relacionadas diretamente à segurança dá ensejo a um contexto muito mais convincente para a análise. $\mathrm{O}$ perigo de que a perspectiva pluralista minimize muito acentuadamente a importância do Estado é real, mas também pode ser superado. Que algumas organizações, 
Reflexões sobre o Lugar do Esporte nas

Relações Internacionais

como o Estado, possam desempenhar um papel de autoridade nas relações interorganizacionais é claramente reconhecido e pode ser incorporado no interior de uma perspectiva pluralista (HOULIHAN, 1994, p. 53).

A dimensão cultural do fenômeno é central, por isso ele destina um capítulo do livro à questão do "esporte, cultura e globalização".

O esporte é o fenômeno cultural mais importante do século XX, é um elemento no processo de globalização da cultura, é um recurso de política externa, e é a arena onde as relações internacionais têm lugar, oferece uma rica variedade de contextos para explorar o significado do esporte na política mundial (HOULIHAN, 1994, p. 52).

De fato, as transformações culturais são da maior importância porque, como lembra Marcel Merle (1981, p. 136), mesmo "os fatos políticos, a começar pelo fato nacional, são em grande parte fatos culturais". Nesse sentido, o Estado-nação não é constituído apenas de um território, uma população e instituições comuns, mas de "um sistema de relações fundamentado sobre a troca constante de inúmeras mensagens pelas quais seus cidadãos se comunicam, de preferência entre si, do que com os cidadãos dos países vizinhos" (MERLE, 1981, p. 136). As informações sobre o mundo exterior sofrem um duplo processo de seleção, o dos órgãos nacionais de informação (jornais, rádios, televisão etc.) e, o que é mais importante, o do próprio público:

O público peneira, seleciona, memoriza, registra ou rejeita as mensagens que lhe chegam, em função de um sistema de valores que lhe serve de certa maneira de grade ou de código para decifrar ou interpretar as informações. Este sistema de valores (ou cultura) está em estreita dependência do sistema educacional e especialmente dos estereótipos alimentados pelo ensi- 


\section{Hugo Suppo}

no da história e da literatura (MERLE, 1981, p. 136).

Isso explicaria, em grande medida, por exemplo, os resultados de recente pesquisa (entrevista de 8 mil pessoas, em 27 Estados e DF), feita em 2011, pela Sport+Markt. Ela revela que os jogadores em atividade mais queridos dos brasileiros são Ronaldinho Gaúcho (26\%) e Neymar $(25,9 \%)$. É interessante destacar que Messi, o melhor do mundo pela FIFA, só obteve 4\% (KNOPLOCH, 2012, p. 8).

Entretanto, esse sistema de valores relativamente fechado, que Merle chama de cultura, foi "deteriorado" pelo desenvolvimento da rede nacional e mundial de comunicação de massa e de informação, com certa uniformização cultural do mundo.

Os debates hoje giram em torno da questão da desintegração ou não dos particularismos culturais e da eventual criação de uma cultura planetária; ${ }^{21}$ o papel das migrações internacionais e as comunicações tornando as identidades extremamente flutuantes e multidimensionais. Mas uma coisa é certa: no mundo globalizado, o esporte, assim como o turismo e o entretenimento, é a única forma de lazer compartilhada por todos. Ele é um elemento essencial na chamada cultura de massas.

Atualmente, o novo sistema midiático globalizado da chamada "era da informação" é um novo campo de enfrentamento onde ocorre o embate entre os Estados, as empresas transacionais e os novos movimentos sociais. O poder, num mundo dominado pelo sistema midiático, consiste em grande parte no controle da produção e na manipulação de símbolos que possam seduzir. Dessa forma, o imenso poder de sedução do esporte e seu impacto econômico ${ }^{22}$ não podem hoje ser ignorados pelos Estados nem pela indústria cultural. Nesse sentido, a geopolítica do esporte encontra-se no centro das disputas e rivalidades nacionais e internacionais, mas também, paradoxalmente, pode servir como vetor da paz $^{23}$ e da cooperação: 
A nível internacional, os acontecimentos desportivos como os Jogos Olímpicos e o Campeonato do Mundo proporcionam as únicas ocasiões, em tempo de paz, durante as quais nações inteiras podem unir-se com regularidade $\mathrm{e}$ de forma visível. A divulgação do desporto a nível internacional tem implicações no aumento da interdependência internacional e da existência, com várias excepções notáveis, de uma paz mundial frágil e instável. Confrontos como os Jogos Olímpicos permitem aos representantes das diferentes nações competirem entre si sem se matarem, ainda que o grau em que semelhantes provas de combates simulados se transformaram em confrontos "reais" esteja dependente, entre outros, do nível de tensão preexistente entre os Estados-nações envolvidos (ELIAS; DUNNING, 1992, p. 325).

O esporte pode ser também considerado um fator positivo na governança global. O homem, que é simultaneamente sapiens, faber e ludens, somente compartilha com o resto dos animais esta última capacidade. O homo ludens gosta de jogar e, com o desenvolvimento da cultura, o jogo se civilizou, o esporte se esportizou, quer dizer, colocou-se ordem e equili brio no jogo por meio de regras escritas, árbitros, tribunais e sanções claramente definidas (ELIAS; DUNNING, 1992, p. 335-336). Norbert Elias chega mesmo a sugerir que deveríamos nos basear no futebol para estudar as relações entre Estados porque ambas são configurações não planejadas e com grandes tensões (ELIAS; DUNNING, 1992, p. 283).

\section{Conclusão}

O esporte foi de fato um tema "negligenciado"24 na área das Relações Internacionais: 


\section{Hugo Suppo}

No entanto, a dimensão esportiva das relações internacionais, muitas vezes, ainda, não desempenha quase nenhum papel na formação no campo da disciplina. Poderíamos esperar não encontrar nenhuma menção ao esporte em alguma coleção com o nome de Clássicos das Relações Internacionais, mas parece estranho não encontrar nenhuma referência ao assunto em monografias e compêndios recentes, como, por exemplo, os manuais International Relations, de Michael Nicholson, e International Relations, de William Nester. Uma honrosa exceção poderia ser o livro International Relations, de Joshua Goldstein, que faz apenas duas referências a organizações internacionais do esporte em uma obra de mais de 600 páginas (ALLISON; MONNINGTON apud ALLISON, 2005, p. 5).

Entretanto, nos últimos anos foram produzidos alguns trabalhos interessantes e inovadores, como, por exemplo, a coleção Sport in the Global Society (Routledge), ${ }^{25}$ dirigida por James Anthony Mangan, ${ }^{26}$ que publicou um número importante de obras sobre temas variados e inovadores (futebol e imprensa, futebol e cultura, as mulheres e o esporte na China, esporte na América Latina, esporte e nacionalismo, a mercantilização do esporte etc). O próprio J. A. Mangan (1998) publicou, nessa coleção, The Games Ethic and Imperialism: Aspects of the Diffusion of an Ideal.

Dois livros dessa coleção chamaram particularmente nossa atenção, e com eles vamos concluir nosso ensaio. O primeiro deles, organizado por Levermore e Budd (2004), é o mais importante, porque é destinado a tratar especificamente do tema: Sport and International Relations. An Emerging Relationship. Nele, após apresentarem um balanço da evolução das pesquisas sobre esporte e relações internacionais, os autores chegam às mesmas conclusões que Trevor Tay- 
Reflexões sobre o Lugar do Esporte nas

Relações Internacionais

lor tinha chegado em 1986: ainda é uma questão completamente negligenciada.

No livro, são abordadas três grandes questões: 1) como a expansão do esporte profissional aliada ao aumento das receitas geradas pela mass media ligada ao esporte transformou a economia política internacional; 2) o papel do esporte na nation building e nas questões de identidade; e 3) o papel do esporte na diplomacia.

Os organizadores do livro elaboraram uma lista de propostas de pesquisas, a maioria delas já desenvolvidas no próprio livro, nos seguintes temas ${ }^{27}$ (LEVERMORE; BUDD, 2004, p. 14): o crescente papel das ONGs do esporte como atores globais não estatais; o papel do esporte na resolução de conflitos internacionais e na diplomacia (propaganda, economia); a construção de regimes globais do esporte e sua influência na interdependência; o esporte como arma de resistência da oposição contra forças dominantes dentro dos países ou por países periféricos contra os países centrais; ${ }^{28}$ o esporte como elemento importante na construção da "comunidade imaginária" nacional $^{29}$ e como instrumento do prestígio nacional no exterior; ${ }^{30}$ o esporte e sua relação com a mudança social e com as novas abordagens das teorias sociais (relação do esporte com o capitalismo, os fenômenos de exclusão-inclusão, o progresso, a modernidade, a discriminação, a identidade ${ }^{31}$ etc.); e esporte e gênero.

O segundo livro, editado por Lincoln Allison (2005), The Global Politics of Sport. The Role of Global Institutions in Sport, desenvolve novos temas, alguns deles já clássicos, mas no contexto atual de globalização do esporte: o papel e o poder das organizações esportivas não governamentais (FIFA, COI etc.); esporte e prestígio; os Jogos Olímpicos; os regimes de regulação do esporte global; esporte e nacionalismo na era global; a americanização do esporte global; a construção de estrelas mundiais do esporte; e o desenvolvimento de 


\section{Hugo Suppo}

tensões dentro de esportes tradicionalmente "alternativos" (por exemplo, o surfe) no contexto da cultura comercial global.

Essas listas de temas e novas abordagens devem ser um estímulo para que nossos estudantes dos cursos de Relações Internacionais tomem consciência da importância e atualidade do assunto, e de como ele oferece um campo enorme para futuras pesquisas num mundo em completa transformação.

\section{Notas}

1. Esta e as demais citações de originais estrangeiros foram livremente traduzidas para este artigo.

2. As "classes médias" preferem o tênis e o golfe.

3. Poderíamos acrescentar um terceiro elemento: as novelas brasileiras.

4. Desde 1894 o COI teve apenas oito presidentes, e em 2013 é o belga Jacques Rogge, que ocupa o cargo desde 2001. Durante a presidência de Juan Antonio Samaranch (de 1980 a 2001), o COI sofreu profundas mudanças por causa da comercialização de artigos comemorativos dos jogos, da venda dos direitos de transmissão dos eventos olímpicos e de patrocínio dos jogos. Dessa forma, o orçamento atinge 2,8 bilhões de dólares (ou seja, o equivalente, por exemplo, ao produto nacional bruto de países como o Mali). Com tamanha concentração de recursos, o COI não poderia ficar imune aos escândalos, como aconteceu, por exemplo, em 1998, na ocasião da designação de Salt Lake City (Estados Unidos) como cidade sede dos Jogos Olímpicos de Inverno 2002, quando sete membros do COI foram excluídos, e outros quatro se demitiram após as denúncias de corrupção se tornarem públicas.

5. Das treze federações internacionais que havia em 1914, o mundo passou a ter 21 em 1918, e 29 em 1932. Grandes competições internacionais são organizadas após a primeira edição dos Jogos Olímpicos de Atenas em 1896: patinagem (1896), tiro (1897), tênis (1900), ginástica (1903), esgrima (1921), ciclismo (1921), bobsleigh (1924), hóquei (1924), tênis de mesa (1927), luta (1929), futebol (1930) e esqui (1937). É importante lembrar que algumas competições 


\section{Reflexões sobre o Lugar do Esporte nas Relações Internacionais}

nacionais contam com grande participação internacional, como o Tour de France (1903) e o Tour d'Italie (o Giro) (1909).

6. Andrew Cooper, cientista político canadense, cunhou o termo "celebrity diplomacy" (diplomacia das celebridades) para analisar o atual engajamento de astros e estrelas em causas e campanhas mundiais. As celebridades esportivas também participam desse movimento: o ex-jogador de futebol Ronaldo, por exemplo, durante vários anos viajou a serviço do Programa das Nações Unidas para o Desenvolvimento (PNUD).

7. Em 2004, a Nike baseara sua campanha de marketing no tema "speed" (velocidade), associando a marca a imagens de atletas patrocinados nas últimas Olimpíadas. O objetivo era atingir um mercado mundial heterogêneo com um produto sem referências geográficas.

8. Nesse sentido, os Jogos Olímpicos são o acontecimento esportivo mais importante porque congregam os esportistas de todos os países, enquanto a Copa do Mundo de Futebol congrega apenas 32 equipes. Nas Olimpíadas, todos os esportes estão representados, até mesmo aqueles que são pouco mediatizados, como a luta e o BMX. A título de comparação: as primeiras Olimpíadas de Atenas, em 1896, contaram com apenas treze nações representadas, totalizando 285 participantes nos nove esportes representados. Em Atenas 2004, participaram 10.500 atletas, representando 201 comitês olímpicos nacionais (a ONU na época contava com 191 Estados participantes). De alguns milhares de espectadores, passou-se a mais de 4 bilhões!

9. Até então, os historiadores das relações internacionais haviam manifestado interesse pelas mentalidades, opinião e ideologias, mas ignoravam as questões culturais propriamente ditas (SUPPO; LESSA, 2007). Dessa forma, o esporte, que é essencialmente uma questão cultural (o lazer), deveria ter sido estudado de forma sistemática na área de Relações Internacionais. Não poderia ter sido de outra forma, já que praticamente todos os Estados desenvolveram, e desenvolvem ainda hoje, uma política cultural externa com o objetivo de procurar influência e prestígio, e o esporte é uma das áreas privilegiadas. Na maioria dos países, antes da criação dos Ministérios do Esporte, era o Ministério da Cultura que se encarregava do esporte.

10. Robert L. Wendzel (1985, p. 205) divide os instrumentos de implementação da política externa em "tangíveis" (econômico e militar) e "intangíveis" (comunicação e negociação). A propaganda faz parte dos instrumentos "intangíveis" da política e pode ser definida como "esforço deliberado para modificar as atitudes e o comportamento de grupos externos, tendo em vista obter dessas audiências-alvos uma reação favorável aos desígnios do propagandista”. Para ser eficiente, a propaganda deve levar em conta os seguintes princípios (que ca- 


\section{Hugo Suppo}

racterizam também os esportes em geral): ser simples, atuar sobre as emoções, significar um interesse direto para o receptor, possuir certo grau de veracidade, ser perceptível e apresentar total identificação com a experiência da população-alvo. As armas da propaganda são as transmissões radiofônicas, os programas de televisão, os artigos e editoriais de jornais, os intercâmbios culturais, os seminários, os artigos de revistas, os panfletos etc.

11. A partir de 1925 , os jornalistas começam a estabelecer quadros comparativos minuciosos das vitórias e das medalhas por país com o objetivo de comparar as diferentes políticas esportivas nacionais. Em 1993, a FIFA criou o ranking mundial das seleções. Desde 2005, a Havas Sports \& Entertainment (HS\&E), agência de marketing esportivo e entretenimento do Grupo Havas, organiza anualmente o estudo "Nations of Sports", em que são levadas em conta as conquistas por países de medalhas em Mundiais e Olimpíadas. Em 2011, foram avaliados 119 países, e os Estados Unidos aparecem em primeiro lugar no ranking, com um total de 548 medalhas, seguido pela China (354) e pela Rússia (330). O Brasil ocupa o $17^{\circ}$ lugar, com 75 medalhas (NOGUEIRA, 2012, p. 5). O Greatest Sporting Nation (http://www.greatestsportingnation.com), site criado em 2008, também elabora um ranking mundial das potências esportivas.

12. Posteriormente, esses textos da revista, acrescidos de alguns outros, foram publicados em um livro (MILZA et al., 2004).

13. Ver Kanin (1981).

14. Informações disponíveis em: $<$ http://www.sais-jhu.edu/academics/regional-studies/europe/faculty/kanin.htm $>$ e $<$ http://turkishcentralnews.com/archives/10363>. Acesso em: 18 jul. 2012.

15. Os autores mais representativos são Robert Cox e Richard Ashley, cada um deles representando, respectivamente, as duas abordagens pós-positivistas radicais mais importantes: a teoria crítica e a corrente pós-modernista.

16. Informações disponíveis em: <https://docs.google.com/viewer?a= v\&q=cache:K_dexNViqGQJ:www.gsuvault.govst.edu/bitstream/10982/ 3069/3/Inscapes1983_08_27.pdf>. Acesso em: 12 jul. 2012.

17. Leitor emérito de Política na Universidade de Warwick e professor visitante de Política do Esporte na Escola Chelsea de Esporte e Lazer da Universidade de Brighton. Foi também fundador, em 1993, do Centro de Estudos do Esporte na Sociedade (WCSSS), da Universidade de Warwick, na Inglaterra.

18. Falecido em fevereiro de 2012 , autor do clássico "O esporte na sociedade soviética" (o primeiro olhar acadêmico sobre o esporte na União Soviética), foi 


\section{Reflexões sobre o Lugar do Esporte nas \\ Relações Internacionais}

professor de estudos russos na Universidade de Surrey, onde foi diretor do Departamento de Linguística e de Estudos Internacionais.

19. Historiador francês especialista em história do esporte e da educação física, professor da Université Claude Bernard, Lyon, onde é fundador e dirige, desde 1985, o Centre de Recherche et d'Innovation sur le Sport (CRIS).

20. Em capítulos que tratam das organizações internacionais do esporte não governamentais e governamentais; o movimento Olímpico; a Commonwealth e o esporte; business e esporte; cultura, esporte e globalização; esporte e política internacional.

21. Nesse sentido, Marcel Merle considera um mito a uniformização cultural do mundo. O que predominam são as reações nacionalistas contra a dominação cultural imposta pelas grandes potências, que controlam os meios de comunicação. Como forma de resistência, muitos países tentam se fechar sobre eles próprios, para defender seu patrimônio cultural.

22. Por exemplo, no Brasil, representa atualmente aproximadamente $1,997 \%$ do PIB, tendo movimentado, em 2010, R \$ 78,6 bilhões, com destaque para os chamados artigos esportivos (SPITZ, 2012, p. 30).

23. A ONU, após ter elaborado em 2003 o relatório "Sport for Development and Peace: Towards Achieving the Millennium Development Goals", declara 2005 Ano Internacional do Esporte e da Educação Física.

24. Em recente publicação (SUPPO, 2012), analisamos como a dimensão cultural das relações internacionais foi interpretada nos diferentes paradigmas teóricos das Relações Internacionais e não encontramos praticamente nenhuma referência ao esporte como fator essencial nas obras clássicas, nem nas abordagens mais recentes, como, por exemplo, o construtivismo.

25. Os livros publicados nessa coleção são baseados nos trabalhos apresentados na conferência da British International Studies Association (BISA), Universidade de Bradford, em dezembro de 2000.

26. Editor do The International Journal of the History of Sport e autor, entre outros livros, de Athleticism in the Victorian and Edwardian Public School (MANGAN, 2000) (a primeira edição é de 1981, em que trata das maneiras como as elites imperiais utilizam o esporte para a aculturação, a socialização e o controle social).

27. Muitos deles já foram tratados anteriormente na bibliografia citada anteriormente. 


\section{Hugo Suppo}

28. A China, na sua atual ofensiva chinesa no continente africano, utiliza o futebol como elemento essencial na sua política de sedução. Por exemplo, quatro estádios usados na Copa das Nações de 2010, disputada em Angola, foram financiados pelos chineses (nas cidades de Luanda, Benguela, Lubango e Cabinda).

29. André Reszler e Alison Browning (1980) elaboraram uma tipologia com sete elementos principais que, combinados, servem para a fabricação da identidade moderna dos Estados: religião, língua, história, mitologia, raça, ideologia e cultura. A esses elementos se somam outros de importância desigual, como, por exemplo, "a idade do povo" (velhas nações versus novas etc.), o messianismo, a extensão territorial, o grau de civilização, o passado histórico, a contribuição à história europeia ou universal e a posição perante as forças do progresso. Já Anne-Marie Thiesse (2000, p. 52) elaborou uma "check-list" identitária matriz de todas as representações de uma nação: ancestrais fundadores, continuidade da nação através das vicissitudes da história, galeria de heróis, língua, monumentos culturais e históricos, lugares de memória, paisagem típica, folclore, identificações pitorescas (costume, gastronomia, animal emblemático). Esses elementos comuns são misturados de forma singular por cada uma das nações na construção de sua identidade. Chama a atenção o fato de que o esporte é simplesmente ignorado por todos esses autores apesar de ele sempre ter sido um elemento identitário importante. De fato, apenas recentemente o esporte fora incorporado a essas listas de elementos identitários pelos especialistas e pelos próprios Estados: "Até os anos sessenta, o esporte representava somente interesse marginal para a maioria dos governos. Antes disso, a intervenção governamental no esporte era geralmente uma reação associada a problemas específicos, como padrões de saúde em áreas urbanas, necessidades militares ou erupções de desordem, e raramente consequência do reconhecimento do esporte (e do lazer) como área política distinta." (VASCONCELLOS, 2011, p. 42).

30. Nesse sentido, são interessantes as observações de Clemens Wergin, editor internacional dos jornais alemães Welt e Welt am Sonntag, quando alertava, poucos dias antes da eliminação da Alemanha da Eurocopa 2012, sobre as consequências ruins para o país caso a Alemanha conquistasse o título. O sucesso alemão reforçaria a imagem de uma nova superpotência no continente. Para Wergin, a seleção deveria perder, fazendo assim "um grande serviço à política externa" do país (WERGIN, 2012, p. 6).

31. Na França, por exemplo, os debates sobre a identidade francesa foram acirrados na última Copa do Mundo de Futebol, quando a seleção nacional fora desqualificada por causa, segundo muitos franceses, da falta de patriotismo dos jogadores, muitos deles negros ou mestiços e descendentes de imigrantes. Ao mesmo tempo, era explicado o sucesso alemão na Copa pela "receita multiétni- 
ca" da seleção, na qual onze dos 23 jogadores eram "estrangeiros" ou descendentes de imigrantes.

\section{Referências} Biblígráficas

ALLISON, Lincoln (Ed.). The Politics of Sport. Manchester: Manchester University Press, 1986.

.The Global Politics of Sport. The Role of Global Institutions in Sport. Londres: Routledge, 2005.

ARNAUD, Pierre. Le sport français face aux régimes autoritaires (1919-1939). In:___ _ RIORDAN, J. Sport et relations internationales (1900-1941). Paris: L'Harmattan, 1998.

Sports et Olympisme après la Premiere Guerre mondiale. Nouvelle donne géopolitique et enjeux de prestige. Relations Internationales, n. 111, p. 347-363, 2002.

BONIFACE, Pascal. Football et mondialisation. Paris: Armand Colin, 2010.

BULL, Heddley. A sociedade anárquica. Brasília: Editora Universidade de Brasília, 2002.

DRUMOND, Maurício. Nações em jogo: esporte e propaganda política em Vargas e Perón. Rio de Janeiro: Apicuri, 2008.

ELIAS, Norbert; DUNNING, Eric. A busca da excitação. Lisboa: Difel, 1992.

HELAL, Ronaldo. Futebol, jornalismo e ciências sociais: interações. Rio de Janeiro: EdUERJ, 2011.

HOBSBAWM, E. A invenção das tradições. Rio de Janeiro: Paz e Terra, 1997.

HOULIHAN, Barrie. Sport and International Politics. Hemel Hempstead: Harvester Wheatsheaf, 1994.

KANIN, D. B. The Olympic System: Transnational Sport Organization and the Politics of Cultural Exchange. In: LOWE, B.; KANIN, D. B.; STRENK, A. 


\section{Hugo Suppo}

(Ed.). Sport and International Relations. Champaign, Illinois: Stipes Publishing Company, 1978. p. 515-537.

A Political History of the Olympic Games. Boulder: Westview Press, 1981.

KELLNER, Douglas. Cultura da mídia e triunfo do espetáculo. In: MORAES, D. de. (Org.). Sociedade midiatizada. Rio de Janeiro: Mauad, 2006. p. 119-147.

KEOHANE, Robert O.; NYE, Joseph S. Transnational Relations and World Politics. Cambridge: Harvard University Press, 1972.

KNOPLOCH, Carol. Uma fábrica de gols e cifrões. Os incríveis números que cercam a meteórica ascensão de Neymar, que se torna um dos maiores fenômenos de marketing do Brasil. O Globo, 29 jan. 2012.

LATTY, Franck. Les Jeux Olympiques et le droit international rendez-vous manqué et rencontres du troisième type. Annuaire François de Relations Internationales, v. X, 2009. Disponível em: <http://www.afri-ct.org >. Acesso em: dez. 2012.

LEVERMORE, Roger; BUDD, Adrian. Sport and International Relations. An Emerging Relationship. Londres: Routledge, 2004.

LOWE, B.; KANIN, D. B.; STRENK, A. (Ed.). Sport and International Relations. Champaign: Stipes Publishing Company, 1978.

MANGAN, J. A. The Games Ethic and Imperialism: Aspects of the Diffusion of an Ideal. Londres: Routledge, 1998.

Athleticism in the Victorian and Edwardian Public School: The Emergence and Consolidation of an Educational Ideology. Londres: Frank Cass, 2000.

MELO, Victor Andrade de; BITTENCOURT, Marcelo; NASCIMENTO, Augusto (Org.). Mais do que um jogo: o esporte e o continente africano. Rio de Janeiro: Apicuri, 2010.

MELO, Victor Andrade de; DRUMOND, Maurício (Org.). Esporte e cinema: novos olhares. Rio de Janeiro: Apicuri, 2009.

MERLE, Marcel. Sociologia das relações internacionais. Brasília: Editora Universidade de Brasília, 1981. 
MILZA, Pierre. Sport et relations internationales. Relations Internationales, n. 38, p. 155-174, 1984.

; JEQUIER, François; TÉTART, Philippe (Dir.). Le pouvoir des anneaux. Les jeux Olympiques à la lumière de la politique 1896-2004. Paris: Vuibert, 2004.

MKHONDO, Rick. Como tolerar a arrogância da FIFA. Diretor de Comunicações do Comitê Organizador da África do Sul ensina os brasileiros. O Globo, 9 mar. 2012.

NOGUEIRA, Claudio. Brasil entre as 20 maiores forças. Sexta economia do mundo e futura sede dos jogos de 2016, país é o $17^{\circ} \mathrm{em}$ um estudo efetuado por agência internacional de marketing. O Globo, 20 jan. 2012.

NYE, Joseph S. O futuro do poder. São Paulo: Benvirá, 2012.

RESZLER, André; BROWNING, Alison. Identité culturelle et relations internationales. (Libres propos sur un grand thème). Relations Internationales, $\mathrm{n}$. 24, p. 381-399, 1980.

RIORDAN, James. Sport, politics, and communism. Manchester: Manchester University Press, 1991.

SHAPIRO, Michael J.; DER DERIAN, J. (Ed.). International/Intertextual Relations - Postmodern Readings of World Politics. Lexington: D. C. Heath, 1989.

SPITZ, Clarice. Em ritmo de jornada nas estrelas. PIB do esporte subiu 6,2\% enquanto o país avançou 3,2\%. O Globo, 26 mai. 2012.

SUPPO, Hugo R. O papel da dimensão cultural nos principais paradigmas das relações internacionais. In: SUPPO, H. R.; LESSA, M. L. (Org.). A quarta dimensão das Relações Internacionais: as relações culturais. Rio de Janeiro: Contra Capa, 2012. p. 7-32.

; LESSA, Mônica L. O estudo da dimensão cultural nas Relações Internacionais: contribuições teóricas e metodológicas. In: LESSA, M. L.; GONÇALVES, W. da S. (Org.). História das relações internacionais: teoria e processos. 1. ed. Rio de Janeiro: EdUERJ, 2007. p. 223-250.

TAYLOR, Trevor. Sport and international relations. A case of mutual neglect. In: ALLISON, L. (Ed.). The politics of sport. Manchester: Manchester University Press, 1986. p. 27-48. 


\section{Hugo Suppo}

THIESSE, Anne-Marie. Des fictions créatrices: les identités nationales. Romantisme, v. 30, n. 110, p. 51-62, 2000.

VASCONCELLOS, Douglas Wanderley de. Esporte, poder e Relações Internacionais. Brasília: Fundação Alexandre de Gusmão, 2011.

WALTZ, Kenneth. Theory of International Politics. Nova Iorque: McGraw-Hill, 1979.

WENDZEL, Robert L. Relações Internacionais. Brasília: Editora Universidade de Brasília, 1985.

WERGIN, Clemens. Vá, lute, mas não vença! Como uma vitória alemã na Eurocopa poderia reforçar imagem de superpotência. O Globo, 21 jun. 2012.

\section{Resumo}

\section{Reflexões sobre o Lugar do Esporte nas Relações Internacionais}

As obras clássicas da disciplina Relações Internacionais praticamente ignoram a questão do esporte. A maioria dos trabalhos sobre as relações entre o esporte e as relações internacionais foi produzida por estudiosos do esporte ou por historiadores das relações internacionais, geralmente sem uma proposta teórica explícita, com primazia das abordagens descritivas e empíricas e com propostas normativas. Apenas recentemente essa "negligência" dos especialistas de Relações Internacionais pelo esporte, mesmo entre aqueles autores que consideravam relevantes os fatores culturais nas suas análises, começou a ter fim. O presente ensaio analisa criticamente os principais temas relativos aos vínculos do esporte com as relações internacionais que foram explorados nos últimos anos, suas implicações e as perspectivas de futuras pesquisas sobre o assunto.

Palavras-chave: Esporte - Relações Internacionais - Cultura - Teoria das Relações Internacionais - História das Relações Internacionais 


\section{Abstract}

\section{Reflections on the Place of Sport in International Relations}

The classic works in the discipline of International Relations virtually ignore the issue of sport. Most studies on the relationship between sport and international relations were produced by scholars of sport or historians of international relations, usually without a explicit theoretical framework, using descriptive approaches and empirical and normative proposals at best. Only recently has this "negligence" of sports by International Relations specialists, even among those authors that take in consideration relevant cultural factors in their analyses, begun to wane. This article critically examines the main recent issues relating to the ties between sport and international relations, their implications and the prospects for future research on the subject.

Keywords: Sports - International Relations - Culture - International Relations Theory - History of International Relations 